\title{
A Novel Fully Differential Second Generation Current Conveyor and Its Application as a Very High CMRR Instrumentation Amplifier
}

\author{
Soma Ahmadi a, Seyed Javad Azhari ${ }^{*}$ \\ ${ }^{a}$ Department of Electrical and Electronic engineering, Iran University of Science and Technology, Tehran, Iran
}

\begin{abstract}
This paper aims to introduce a novel Fully Differential second generation Current Conveyor (FDCCII) and its application to design a novel Low Power (LP), very high CMRR, and wide bandwidth (BW) Current Mode Instrumentation Amplifier (CMIA). In the proposed application, CMRR, as the most important feature, has been greatly improved by using both common mode feed forward (CMFF) and common mode feedback (CMFB) techniques, which are verified by a perfect circuit analysis. As another unique quality, it neither needs well-matched active blocks nor matched resistors but inherently improves CMRR, BW, and power consumption hence gains an excellent matchless choice for integration. The FDCCII has been designed using 0.18 um TSMC CMOS Technology with \pm 1.2 $\mathrm{V}$ supply voltages. The simulation of the proposed FDCCII and CMIA have been done in HSPICE LEVEL 49. Simulation results for the proposed CMIA are as follow: Voltage CMRR of $216 \mathrm{~dB}$, voltage CMRR BW of $300 \mathrm{~Hz}$. Intrinsic resistance of X-terminals is only $45 \Omega$ and the power dissipation is $383.4 \mu \mathrm{W}$. Most favourably, it shows a constant differential voltage gain BW of 18.1 $\mathrm{MHz}$ for variable gains (here ranging from $0 \mathrm{~dB}$ to $45.7 \mathrm{~dB}$ for example) removing the bottleneck of constant gain-BW product of Voltage mode circuits.
\end{abstract}

\section{Keywords:}

Current-mode;

Instrumentation Amplifier;

CMIA;

FDCCII;

Very High CMRR.

\section{Article History:}

Received: 26 November 2017

Accepted: 19 March 2018

\section{1- Introduction}

In the last decades, researchers and designers of analog processors have been faced with serious challenges in the design of low-voltage (LV), low-power (LP) circuits and systems. That is due the increasing demand for mobile and battery powered equipment and also technology down scaling trend [1]. Current mode (CM) signal processing/design as a promising solution to these challenges has thus gained more popularity [1-5]. As the main reason of the superiority of CM processors over the Voltage Mode (VM) ones can name: the wider dynamic range, simpler circuitry, wider BW, higher speed/frequency, lower supply voltage and consumed power [4-14]. Besides, while the Voltage Mode Instrumentation Amplifiers (VMIA) seriously suffer from problems of dependency of BW on gain and CMRR value, and need tightly matched resistor (to improve the CMRR), most favorably, the Current Mode Instrumentation Amplifiers (CMIA) are free from such requirements [6-18]. Various structures of CMIA have yet been reported, among which CMIAs based on FDCCIIs take the lead; because these structures are free from well-matched active blocks, as well as matched resistors to gain a high CMRR. The second generation current conveyors (CCIIs) are active blocks that have been used in many analog circuits such as oscillators [19-23], active filters [24-26] and amplifiers [6-18] to grant current mode benefits. The fully differential type of CCIIs [19-22] benefits from differential input and output terminals that are strongly acknowledged today. In this paper we seek to design a novel FDCCII structure to realize a high CMRR IA.

\section{2- Proposed FDCCII}

Functional block diagram and operational matrix of an ideal FDCCII are shown in Figure 1 and Equation 1, respectively.

\footnotetext{
*CONTACT: Azhari@iust.ac.ir

DOI: http://dx.doi.org/10.28991/esj-2018-01131

(C) This is an open access article under the CC-BY license (https://creativecommons.org/licenses/by/4.0/).
} 


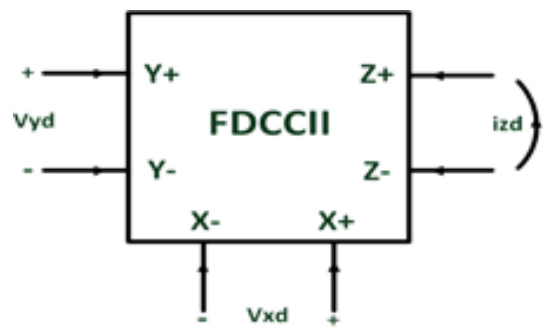

Figure 1. Block diagram of FDCCII.

$$
\left[\begin{array}{c}
\mathrm{i}_{\mathrm{y}+} \\
\mathrm{i}_{\mathrm{y}-} \\
\mathrm{v}_{\mathrm{x}+} \\
\mathrm{v}_{\mathrm{x}-} \\
\mathrm{i}_{\mathrm{z}+} \\
\mathrm{i}_{\mathrm{z}-}
\end{array}\right]=\left[\begin{array}{cccccc}
0 & 0 & 0 & 0 & 0 & 0 \\
0 & 0 & 0 & 0 & 0 & 0 \\
1 & 0 & 0 & 0 & 0 & 0 \\
0 & -1 & 0 & 0 & 0 & 0 \\
0 & 0 & 1 & 0 & 0 & 0 \\
0 & 0 & 0 & -1 & 0 & 0
\end{array}\right]\left[\begin{array}{c}
\mathrm{v}_{\mathrm{y}+} \\
\mathrm{v}_{\mathrm{y}-} \\
\mathrm{i}_{\mathrm{x}+} \\
\mathrm{i}_{\mathrm{x}-} \\
\mathrm{v}_{\mathrm{z}+} \\
\mathrm{v}_{\mathrm{z}-}
\end{array}\right]
$$

Given Figure 1 and Equation 1, ideal FDCCIIs are current mode building blocks with six terminals that named as $\mathrm{Y}_{+}, \mathrm{Y}_{-}, \mathrm{X}_{+}, \mathrm{X}_{-}, \mathrm{Z}_{+}$and $\mathrm{Z}$. Ideally the differential voltage of the $\mathrm{X}$-terminals, $\mathrm{V}_{\mathrm{xd}}$, follows the differential voltage of the Y-terminals, $V_{y d}$, and the differential current of the Z-terminals, $i_{z d}$, follows the differential current of the $X$-terminals, $\mathrm{i}_{\mathrm{xd}}$. It means that ideal input impedance of Y-terminals, input (output) impedance of X-terminals and output impedance of Z-terminals are infinite, zero, and infinite, respectively. In real conditions, undesirable effects in FDCCII's function results from the non-ideal impedances in these terminals.

The CMOS transistor level realization of the proposed FDCCII is shown in Figure 2. Since this FDCCII has been intended for applications of instrumentation amplifier, thus, the design has been focused to improve its voltage CMRR. Like the most of already reported FDCCIIs, the voltage following operation of this FDCCII depends on the equalizing rate of output currents of two included transconductors. Practically, transistors M1-M2 and M5-M6 as the differential pairs of input stage transconductors must be tightly matched for a unity differential voltage gain from $\mathrm{Y}$ to $\mathrm{X}$ terminal. This differential pairs share the active loads M25-M26.

The transistors M4, M7 have been employed to fix common mode voltage of nodes B and C by using CMFF technique resulting in voltage CMRR improvement (by the factor of $\varepsilon_{4}$, as is explained in section 3). Actually these pairs, in addition to current mirror M24-M26, generate currents equal to common mode currents of M2 and M5 result in fix common mode voltages of nodes B and C. Moreover, the transistors M3 and M8 have been employed to fix common mode voltages of nodes $\left(\mathrm{X}_{+}, \mathrm{X}_{-}\right)$and $(\mathrm{B}, \mathrm{C})$ by using $\mathrm{CMFB}$ technique results in voltage CMRR improvement. Any common mode voltage at X-terminals causes common mode currents in $\mathrm{M} 3$ and $\mathrm{M} 8$ that along with current mirror M24-M26 generate the same currents in transistors M25-M26 resulting in fixated common mode voltages at nodes $\left(\mathrm{X}_{+}\right.$, $\mathrm{X}$ ) and $(\mathrm{B}, \mathrm{C})$ (by the factor of $\varepsilon_{4}$, as is explained in section 3). To prevent the common mode voltage amplifying in drains of M11 (dM11) and M12 (dM12) (by the factor of $\varepsilon_{5}+\varepsilon_{6}$, as is explained in section 3), a CMFF technique has been employed as the pair of M29-M30 and current mirrors of M11-M13 as follows: The pair of M29-M30 apply a current equal to the common mode current of M27 and M28 to current mirror M11-M13, then there is no common mode current passing through impedances of nodes dM11 and dM12. Transistors M21-M22 that must be matched for symmetry, are the voltage buffer stages. Two identical class-A output stages consisting of M33 and M34 are the current buffer stages. These stages mirror X-terminals differential current to Z-terminals and for a unity differential current gain must be matched with corresponding transistors of the X-terminals branches (M31-M32). In the current following action of the output stages, simple current mirror M18-M20 along with transistors M35-M36 remove common mode currents passing through Z-terminals (by the factor of $\varepsilon_{2}+\varepsilon_{3}-\varepsilon_{1}$ as is explained in section 3) using the same CMFF technique as the one is already explained.

Driving the mentioned current buffer and voltage buffer blocks (see Figure 2) are determined by $\mathrm{v}_{\mathrm{ocm}}$ which is generated by the CMFB block consisting of current mirror M16-M17 and differential pair of M37-M38 (see Figure 2). 


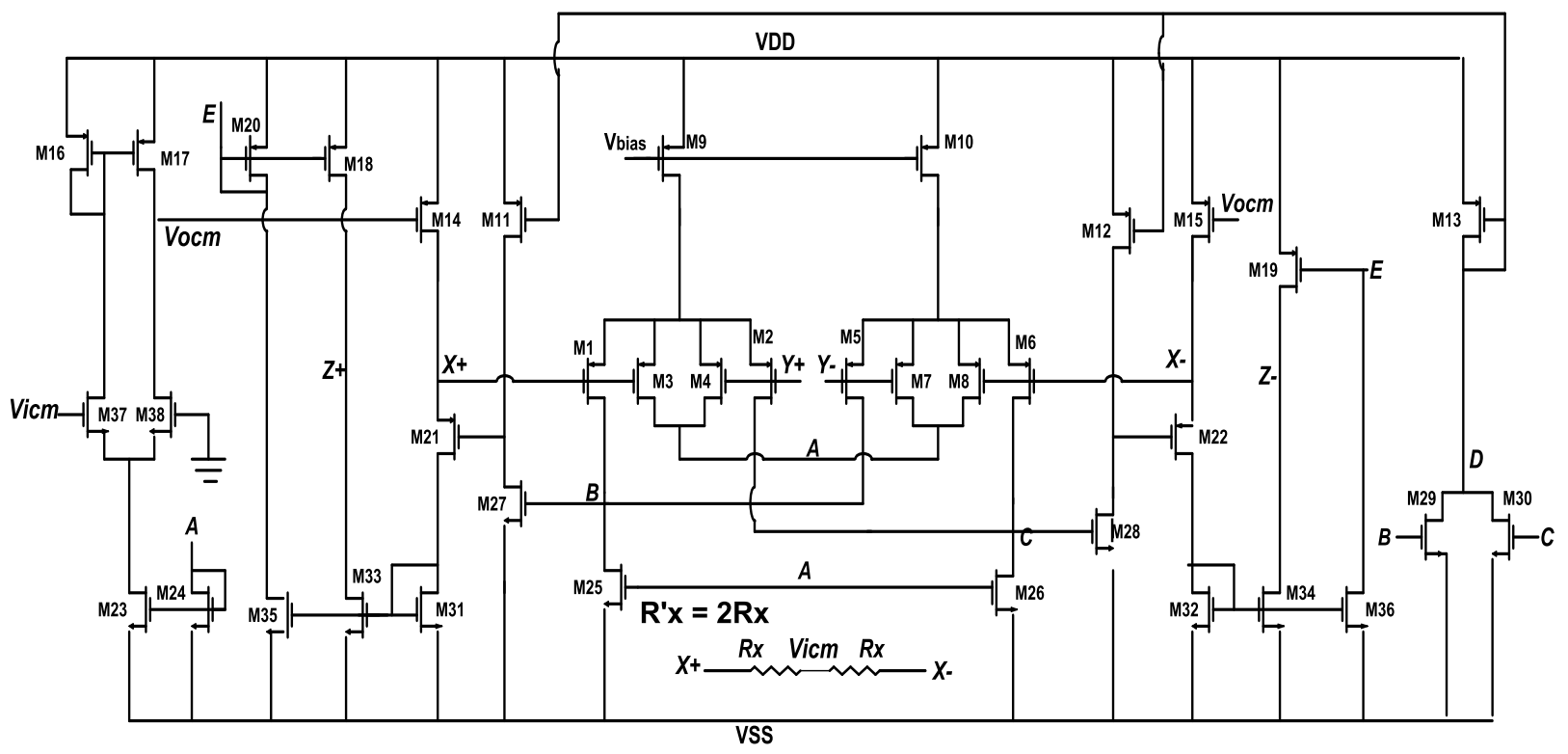

Figure 2. Transistor level structure for proposed FDCCII.

Function of the CMFB block is to fix common mode voltage of X-terminals to zero using negative feedback structure. By applying common mode voltage to Y-terminals, the common mode voltage of $\mathrm{X}$-terminals is increased which flows a common mode current in the external resistance of $\mathrm{Rx}$ and increasing the common mode voltage in node $\mathrm{V}_{\mathrm{icm}}$. This increased voltage stimulates differential pair of M37-M38 to increase $\mathrm{V}_{\mathrm{ocm}}$, resulting in identical common mode currents in M14-M15. Finally, this negative feedback prevents the passing of input common mode current through M21-M22 resulting in great improvement of CMRR. It is worth mentioning that in this work, $\mathrm{R}^{\prime} \mathrm{x}$ is an external resistor placed between $\mathrm{X}$ terminals (that is shown as two series resistors of Rx in Figure 2) to form the suitable $\mathrm{X}$ inputs and $\mathrm{Z}$ outputs currents, thus should sufficiently be larger than internal resistance of X-terminals $\left(\mathrm{r}_{\mathrm{x}}\right)$.

\section{3- Circuit Equations}

In this section, a full small signal analysis of the circuit performance is expressed. All transistors of the novel FDCCII are assumed to be operating in saturation region. It should be noticed that transistors M11-M12, M14-M15, M18-M19 and M25-M26 function as constant and variable current sources respectively for differential and common mode inputs. This is because of parallel connected pairs of M3-M4, M7-M8, M29-M30, M35-M36 (which don't respond to differential inputs) and $\mathrm{V}_{\text {icm }}$ which is zero for differential inputs.

If differential voltage of $Y_{+}-Y_{-}=V_{d}\left(Y_{+}=-Y_{-}=V_{d} / 2\right)$ is applied to $Y$-terminals, Equations 2 to 4 could be concluded for FDCCII circuit (in this case $\mathrm{g}_{\mathrm{m} 5-8}=\mathrm{g}_{\mathrm{m} 5}$ and $\mathrm{g}_{\mathrm{m} 1-4}=\mathrm{g}_{\mathrm{m} 1}$ and no $R_{X}^{\prime}$ between X-terminals are assumed):

$$
\begin{aligned}
& V_{(B)}=-V_{(C)}=\left(i_{a c 1}+i_{a c 6}\right) R_{o u t B}=-g_{m 1} \cdot R_{o u t B} \frac{Y_{+}-Y_{-}}{2}-g_{m 2} \cdot R_{o u t B} \frac{X_{-}-X_{+}}{2} \\
& V_{d M 11}=-V_{d M 12}=-i_{a c 27} R_{o u t d M 11}=-g_{m 27} \cdot R_{\text {outd } M 11} \cdot V_{(B)} \\
& V_{\text {xadiff }}=-V_{\text {xbdiff }}=V_{d M 11} \cdot \frac{r_{o 14}}{r_{o 14}+\frac{1}{g_{m 21}}}=-V_{d M 12} \cdot \frac{r_{o 14}}{r_{o 14}+\frac{1}{g_{m 21}}}
\end{aligned}
$$

Using Equations 2 to 4, differential voltage gain from Y-terminals to X-terminals (while there is no external resistor $R_{X}^{\prime}$ between X-terminals) can be found as Equation 5:

$$
A v_{\text {xdiff }}=\frac{V_{\text {xdiff }}}{V_{\text {indiff }}}=\frac{g_{m 1} \cdot g_{m 27} R_{\text {outB }} \cdot R_{\text {outC }} \frac{r_{o 14}}{r_{o 14}+\frac{1}{g_{m 21}}}}{1+g_{m 5} \cdot g_{m 27} R_{\text {outB }} \cdot R_{\text {outC }} \frac{r_{\text {o14 }}}{r_{\text {o14 }}+\frac{1}{g_{m 21}}}} \approx \frac{g_{m 1}}{g_{m 5}}
$$

Assuming $\mathrm{g}_{\mathrm{m} 1}=\mathrm{g}_{\mathrm{m} 5}$, results a unity differential voltage gain from $\mathrm{Y}$ to $\mathrm{X}$ terminals. Using loop gain of differential negative feedback (c.f. denominator of Equation 5) assists to find X-terminals intrinsic floating resistance 
$r_{x}=\frac{2\left(r_{o 14} / / \frac{1}{g_{m 21}}\right)}{1+g_{m 5} \cdot g_{m 27} \cdot R_{\text {outB }} \cdot R_{\text {outC }} \frac{r_{o 14}}{r_{o 14}+\frac{1}{g_{m 21}}}}$

Because of unity differential current gain of the output stage, the differential voltage gain from Y-terminals to each one of Z-terminals (when there are external resistor of $R_{X}^{\prime}$ between X-terminals and external grounded loads of $R_{Z}$ at Zterminals) could be expressed as Equation 7:

$A v_{z d i f f} \cong \frac{g_{m 1}}{g_{m 5}} \cdot \frac{R_{Z}}{R_{X}^{\prime}+r_{x}}$

Assuming $\mathrm{g}_{\mathrm{ml}}=\mathrm{g}_{\mathrm{m} 5}$ and a constant $R_{X}^{\prime}$, the differential voltage gain of $A v_{\text {zdiff }}$ of Equation 7 becomes mainly determined by the ratio of $\mathrm{R}_{\mathrm{Z} / /} r_{x}$. Similarly, if common mode voltages of $\mathrm{Y}+=\mathrm{Y}-=\mathrm{V}_{\mathrm{cm}}$ are applied to the voltage inputs of the FDCCII, the small signal equations for conveying input signals to $\mathrm{X}$-terminals can be expressed as follows (assuming, $\mathrm{g}_{\mathrm{m} 1}=\mathrm{g}_{\mathrm{m}}$ ):

$$
\begin{aligned}
& V_{(B)}=V_{(C)}=\left(i_{1 c m}+i_{5 c m}-i_{25 c m}\right) R_{\text {outB }}=-\varepsilon_{c 4} \cdot R_{\text {outB }} \cdot \frac{g_{m 1}}{1+4 g_{m 1} \cdot r_{o 9}}\left(V_{\text {incm }}+V_{x c m}\right) \\
& V_{d M 11}=V_{d M 12}=\left(i_{11 c m}-i_{27 c m}\right) R_{\text {outdM11 }} \cong\left(\varepsilon_{c 5}+\varepsilon_{c 6}\right) R_{\text {outdM11 }} \cdot g_{m 27} \cdot V_{(B)} \\
& V_{x+c m}=V_{d M 11} \frac{g_{m 21} g_{m 31}}{g_{m 31}\left(g_{m 21}+r_{o 21}\right)-\frac{g_{m 31}+r_{o 21}}{r_{o 14} / / R_{x}}}
\end{aligned}
$$

From Equations 8 to 10, common mode voltage gain to X-terminals is as follows:

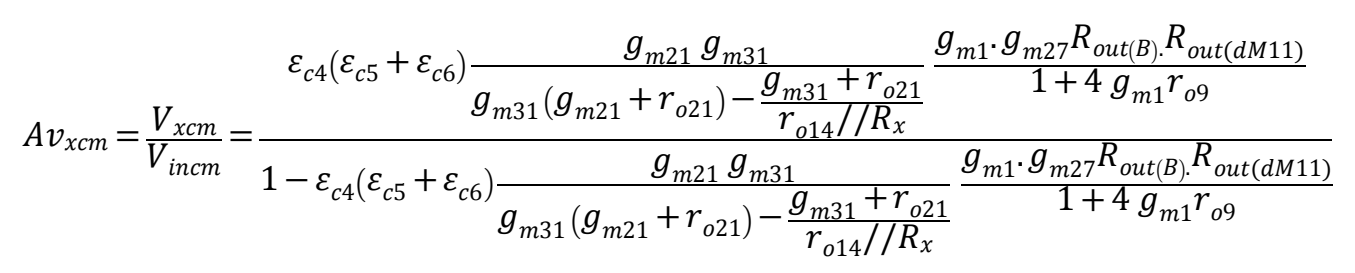

Now the total common mode voltage gain from Y-terminals to Z-terminals (while there are external resistor of $R_{X}^{\prime}$ between X-terminals and external grounded loads of $\mathrm{Rz}$ at Z-terminals) can be concluded as Equation 11:

$$
A v_{z c m}=\frac{i z_{c m} \cdot R_{z}}{V_{\text {incm }}} \cong \frac{\varepsilon_{c 4}\left(\varepsilon_{c 5}+\varepsilon_{c 6}\right) \times\left(\varepsilon_{c 2}+\varepsilon_{c 3}-\varepsilon_{c 1}\right) g_{m 1} \cdot g_{m 21} \cdot g_{m 27} \cdot R_{\text {out }(B) \cdot R_{\text {out }(d M 11)} \cdot R_{Z}}}{1+4 g_{m 1} r_{o 9}}
$$

Loop gain of feedback in the denominator of Equation 11 is very smaller than "one", thus, can be ignored. Finally using Equations 6 and 12 gives voltage CMRR as Equation 13:

$$
C M R R_{V}=\frac{A v_{z d i f f}}{A v_{z c m}} \cong \frac{1+4 g_{m 1} r_{o 9}}{\varepsilon_{c 4}\left(\varepsilon_{c 5}+\varepsilon_{c 6}\right) \times\left(\varepsilon_{c 2}+\varepsilon_{c 3}-\varepsilon_{c 1}\right) g_{m 5} \cdot g_{m 21} \cdot g_{m 27} \cdot R_{\text {out }(B) \cdot} R_{\text {out }(d M 11)}\left(R_{x}+r_{x}\right)}
$$

Transistors dimensions of the proposed FDCCII is shown in Table 1. The dimensions have been optimized for loads of $\mathrm{R}_{\mathrm{z}^{+}}=\mathrm{R}_{\mathrm{z}-}=\mathrm{R}_{\mathrm{L}}=1 \mathrm{k} \Omega$.

Table 1. Dimension of the transistors of the proposed FDCCII.

\begin{tabular}{ll}
\hline Transistors & W/L $(\boldsymbol{\mu m} / \boldsymbol{\mu m})$ \\
\hline M1-M8 & $6 / 0.45$ \\
M9-M10 & $24.8 / 0.8$ \\
M11-M13 & $1.26 / 0.45$ \\
M14-M15 & $5 / 0.5$ \\
M16-M17 & $8 / 1.7$ \\
M18-M19 & $0.47 / 0.6$ \\
M20 & $0.47 / 0.9$ \\
M21-M22 & $13.5 / 0.7$
\end{tabular}




\begin{tabular}{ll} 
M23, M25-M26, M27-M28 & $6.48 / 1.53$ \\
M24 & $12.96 / 1.53$ \\
M29-M30 & $3.24 / 1.53$ \\
M31-M34 & $0.77 / 1.9$ \\
M35-M36 & $0.3 / 2$ \\
M37-M38 & 1.170 .9 \\
\hline
\end{tabular}

\section{4- Proposed CMIA and Simulation Results}

The novel FDCCII has been improved specifically towards the application of instrumentation amplifier. Thus it can be used alone as an IA when both of its Z-terminals are connected to a grounded load resistor $\mathrm{R}_{\mathrm{L}}$. Configurations of the proposed CMIA for voltage input case is shown in Figure 3.

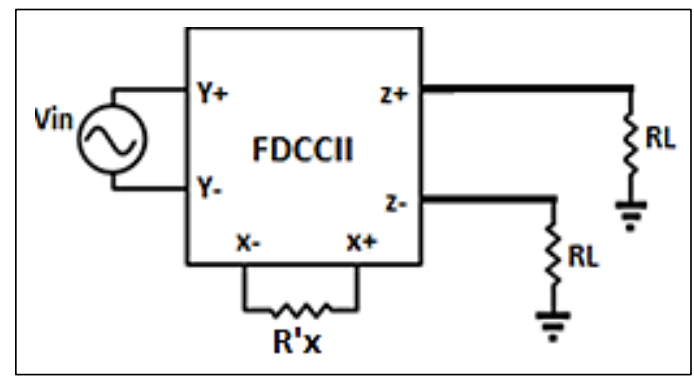

Figure 3. CMIA configuration for voltage inputs.

The most important specifications of the proposed circuit have been evaluated using HSPICE LEVEL 49 in 0.18 um TSMC CMOS Technology. It should be noticed that $R_{X}^{\prime}=0.44 \mathrm{k} \Omega$ and $\mathrm{V}_{\text {bias }}=600 \mathrm{mV}$ (bias voltage connected to gate of M9 in Figure 2) has been used in the simulations. The results of the frequency response simulation at the several gains are shown in Figure 4 for voltage input case. Different gains are obtained (from $0 \mathrm{~dB}$ to $45.7 \mathrm{~dB}$ ) using different values of the load resistors $\mathrm{R}_{\mathrm{L}}\left(\mathrm{R}_{\mathrm{L}}=0.44 K \Omega-150 K \Omega\right)$. It can be seen that the $\mathrm{BW}$ is constant as $18.1 \mathrm{MHz}$ for different gains (the amount of $\mathrm{R}_{\mathrm{L}}$ to maintain the same $\mathrm{BW}$ for differential voltage gain is limited to $150 \mathrm{~K} \Omega$ ). Favorably, Figure 4 shows that in the designed FDCCII there is no dependency between BW and gain, which exists in Voltage Mode (VM) circuits; the variation in the RL that results in the same variation in the voltage gain has no effect on the BW. The frequency responses of the voltage CMRR is shown in Figure 5. As it can be seen in Figure 5, the proposed CMIA has a CMRR of $216 \mathrm{~dB}$ with $-3 \mathrm{~dB}$ BW of $300 \mathrm{~Hz}$; with $R_{L}=1 \mathrm{~K} \Omega, R_{X}^{\prime}=0.44 \mathrm{~K} \Omega$.

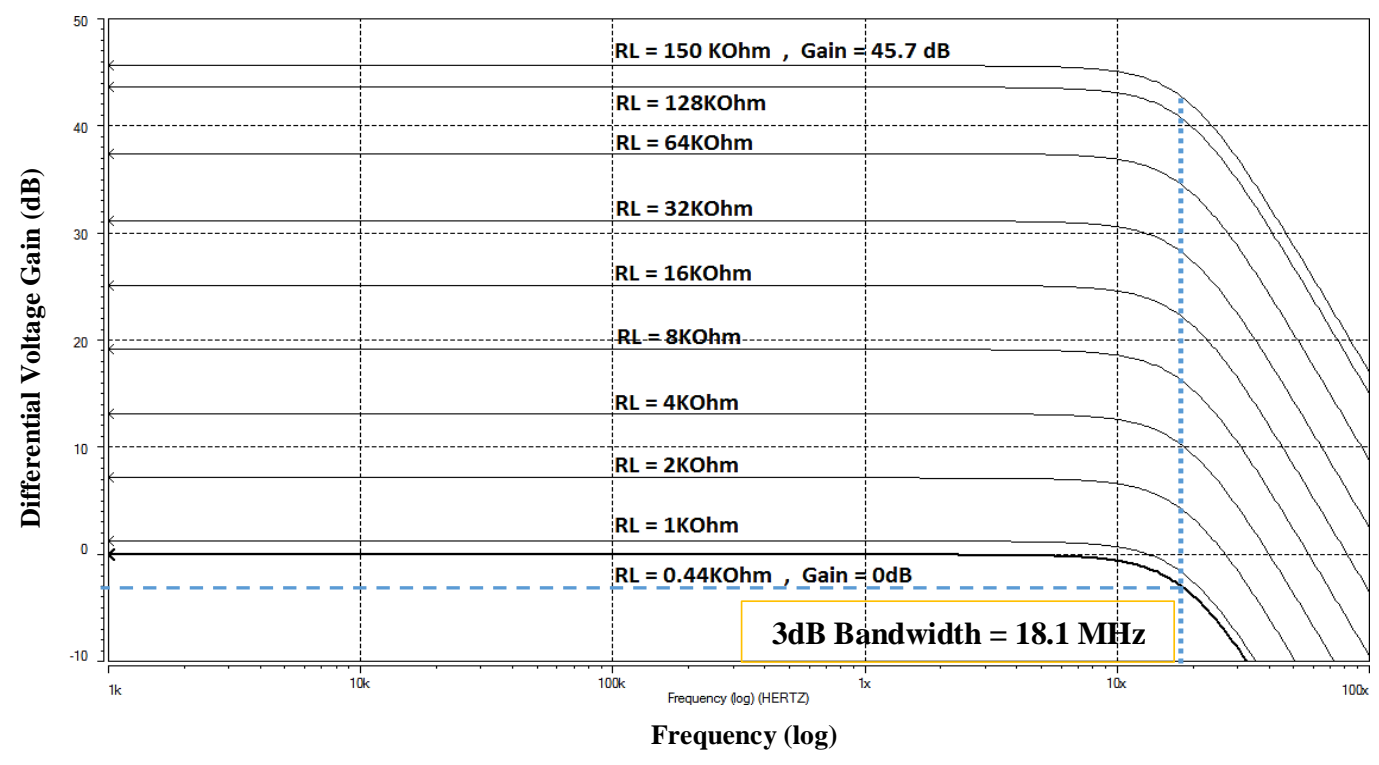

Figure 4. Frequency response of the voltage differential gains for different values of RL (.44K $\Omega-150 \mathrm{~K} \Omega)$. 


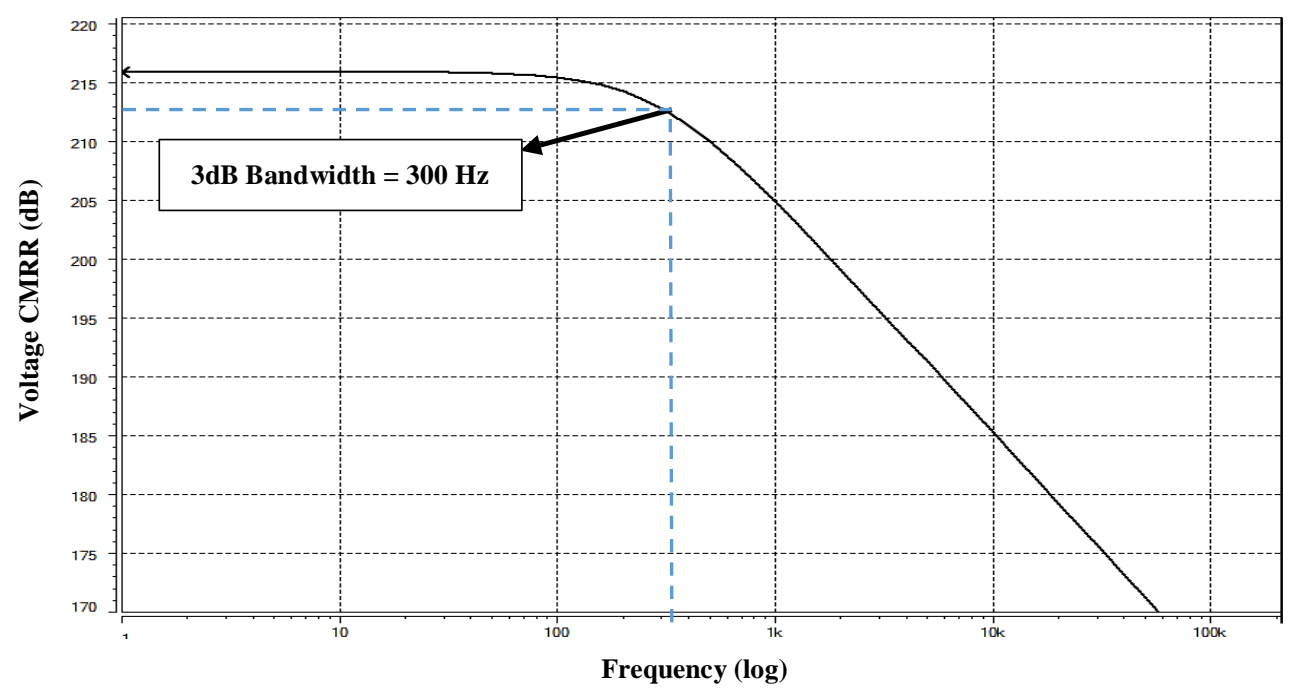

Figure 5. Voltage CMRR for proposed CMIA with $\mathrm{RL}=1 \mathrm{~K} \Omega, \mathrm{R}^{\prime}{ }_{X}=0.44 \mathrm{~K} \Omega$.

Table 2 summarizes the performance simulation results of the proposed CMIA. Differential voltage gain varies from $0 \mathrm{~dB}\left(\mathrm{R}_{\mathrm{L}}=0.44 \mathrm{~K} \Omega\right)$ to $45.7 \mathrm{~dB}\left(\mathrm{R}_{\mathrm{L}}=150 \mathrm{~K} \Omega\right)$. Power consumption under $\pm 1.2 \mathrm{~V}$ supply voltage is only $383.4 \mu \mathrm{W}$, and $\mathrm{X}-$ terminals intrinsic floating resistance $\left(r_{x}\right)$ is $45 \Omega$. The performance comparison between the proposed CMIA and some other artworks is summarized in Table 3.

Table 2. CMIA's performance specifications.

\begin{tabular}{ll}
\hline Voltage CMRR & $216 \mathrm{~dB}$ \\
CMRR 3dB Bandwidth & $300 \mathrm{~Hz}$ \\
Differential Voltage Gain Bandwidth $\left(\mathbf{R}_{\mathbf{L}} \leq \mathbf{1 5 0 K} \boldsymbol{\Omega}\right)$ & $18.1 \mathrm{MHz}$ \\
Differential Voltage Gain $\left(\mathbf{0 . 4 4 K} \mathbf{\Omega} \leq \mathbf{R}_{\mathbf{L}} \leq \mathbf{1 5 0 K} \mathbf{\Omega}\right)$ & $0 \mathrm{~dB}-$ to $-45.7 \mathrm{~dB}$ \\
Differential Voltage Gain Bandwidth product $(\mathbf{M H z})$ & $18.1 * 10^{6}$-to- $3.49 * 10^{9}$ \\
Power Dissipation & $383.4 \mu \mathrm{W}$ \\
Supply Voltages & $\pm 1.2 \mathrm{~V}$ \\
X-terminals intrinsic floating resistance $\left(\boldsymbol{r}_{\boldsymbol{x}}\right)$ & $45 \Omega$ \\
\hline
\end{tabular}

As it can be seen in Table 3, the proposed CMIA exhibits superior performance in terms of CMRR value and differential gain BW for voltage input, very low $\left(r_{x}\right)$ and low consumed power. Also, it doesn't need matched blocks.

Table 3. Comparison between the proposed CMIA and some other works

\begin{tabular}{|c|c|c|c|c|c|c|c|}
\hline Specification & {$[18]$} & {$[17]$} & [17] & [8] & [11] & {$[13]$} & Proposed \\
\hline Input Signal & Voltage & Voltage & Voltage & Voltage & Voltage & Current & Voltage \\
\hline Technology & $65 \mathrm{~nm}$ CMOS & $130 \mathrm{~nm}$ CMOS & $90 \mathrm{~nm}$ CMOS & 0.18um CMOS & 0.35um CMOS & 0.18um CMOS & 0.18 um CMOS \\
\hline CMRR & $88 \mathrm{~dB}^{\mathrm{v}}$ & $64.7 \mathrm{~dB}^{\mathrm{v}}$ & $76 \mathrm{~dB}^{\mathrm{v}}$ & $110 \mathrm{~dB}^{\mathrm{v}}$ & $107 \mathrm{~dB}^{\mathrm{v}}$ & $91 \mathrm{~dB}^{\mathrm{c}}$ & $216 \mathrm{~dB}$ \\
\hline $\begin{array}{c}\text { CMRR } \\
\text { Bandwidth } \\
\end{array}$ & $<6 \mathrm{KHz}$ & $100 \mathrm{KHz}$ & $14 \mathrm{KHz}$ & $\mathrm{NA}^{\mathrm{e}}$ & $\mathrm{NA}^{\mathrm{e}}$ & $1.15 \mathrm{kHz}^{\mathrm{c}}$ & $300 \mathrm{~Hz}$ \\
\hline $\begin{array}{c}\text { Differential } \\
\text { Voltage Gain }\end{array}$ & $<39 \mathrm{~dB}$ & $<61 \mathrm{~dB}$ & $<50 \mathrm{~dB}$ & $0 \mathrm{~dB}$ & $0 \mathrm{~dB}$ & $0 \mathrm{~dB}$ & $0 \mathrm{~dB}$-to- $45.7 \mathrm{~dB}$ \\
\hline $\begin{array}{c}\text { Differential } \\
\text { Gain BW } \\
\text { product }\end{array}$ & $\mathrm{NA}^{\mathrm{e}}$ & $<381 \mathrm{MHz}$ & $<56.9 \mathrm{MHz}$ & $\mathrm{NA}^{\mathrm{e}}$ & $8 \mathrm{MHz}^{\mathrm{v}}$ & $10.18 \mathrm{MHz}^{\mathrm{c}}$ & $\begin{array}{l}\text { 18.1 MHz to } \\
3.49 \mathrm{GHz}\end{array}$ \\
\hline $\begin{array}{c}\text { Power } \\
\text { Dissipation }\end{array}$ & $3.96 \mu \mathrm{W}$ & $14 \mu \mathrm{W}$ & $11 \mu \mathrm{W}$ & $420 \mu \mathrm{W}$ & $1.3 \mathrm{~mW}$ & $219 \sim 446 \mu \mathrm{W}$ & $383.4 \mu \mathrm{W}$ \\
\hline Supply Voltages & $1.2 \mathrm{~V}$ & $0.4 \mathrm{~V}$ & $0.4 \mathrm{~V}$ & $\pm 1.65 \mathrm{~V}$ & $\pm 1.5 \mathrm{~V}$ & $\pm 0.8 \mathrm{~V}$ & $\pm 1.2 \mathrm{~V}$ \\
\hline $\begin{array}{c}\text { Needs Matched } \\
\text { Blocks }\end{array}$ & Yes & No & No & Yes & No & No & No \\
\hline
\end{tabular}

${ }^{\mathrm{c}}$ for current input, ${ }^{\mathrm{v}}$ for voltage input, ${ }^{\mathrm{e}}$ not available 


\section{0- Conclusion}

In this paper, a novel topology of a low power, very high CMRR, and wide BW CMIA is introduced. Its structure is based on one active block named FDCCII, which is designed based on novel structures and techniques, that eliminates the need for well-matched blocks to reach a very high CMRR for the proposed CMIA. The results of HSPICE simulations show that the CMRR value and BW as the most important properties of CMIAs, are greatly improved using CMFB and CMFF techniques. Because of its low power dissipation it can also be used for portable systems and well matched the down scale trend of the modern technologies.

\section{2- References}

[1] A.J. Annema, B. Nauta, R.V. Langevelde, H. Tuinhout, Analogue circuits in ultra-deep- submicron CMOS. IEEE J. Solid-State Circuits, Vol. 40, 2005, pp.132-143. DOI: 10.1109/JSSC.2004.837247.

[2] C. Toumazou, F. J. Lidgey, and D. G. Haigh, Analogue IC Design: The Current-Mode Approach, London, U.K., IEE Press, 1990.

[3] G. Ferri and N.C. Guirrini, Low-Voltage, Low-Power CMOS Current Conveyors (Chap.4), Kluwer 2003.

[4] Archana, S., B. K. Madhavi, and IV Murali Krishna. "Design of CMOS current mode and voltage mode Winner Take all circuit on 180nm technology." Electrical, Electronics, and Optimization Techniques (ICEEOT), International Conference on. IEEE, 2016. DOI: 10.1109/ICEEOT.2016.7755014.

[5] Broomandnia, Hassan, and Seyed Javad Azhari. "Design of a fully differential current buffer (FDCB) based on a new common mode feedforward (CMFF) based common mode separation technique." Knowledge-Based Engineering and Innovation (KBEI), 2015 2nd International Conference on. IEEE, 2015. DOI: 10.1109/KBEI.2015.7436074.

[6] E. L. Douglas et al., A low-voltage current-mode instrumentation amplifier designed in a 0.18-micron CMOS technology, in Proc. IEEE CCECE-CCGEI, May. 2004, pp. 1777-1780. DOI: 10.1109/CCECE.2004.1349760.

[7] S.J.Azhari, and H.Fazlalipoor, CMRR in Voltage-Op-Amp-Based Current-Mode Instrumentation Amplifiers (CMIA), IEEE TRANSACTIONS ON INSTRUMENTATION AND MEASUREMENT, VOL. 58, 2009, pp. 563-569. DOI: 10.1109/TIM.2008.2005559.

[8] A. Voulkidou, S. Siskos, and T. Laopoulos, A Low Noise Low Offset Current Mode Instrumentation Amplifier, 19th International Conference Mixed Design of Integrated Circuits and Systems, May 24-26, 2012, pp. 203-207.

[9] B.Babaei and S.Mirzakuchaki, High CMRR, Low Power and Wideband Current-Mode Instrumentation Amplifier, in Proc. IEEE Int. Norchip Conference, 2006, pp.3-4. DOI: 10.1109/NORCHP.2006.329258.

[10] S.J. Azhari and H. Fazlalipoor, A novel current mode instrumentation amplifier (CMIA) topology, IEEE Transactions on Instrumentation and Measurement, 49, 2000, pp. 1272-1277. DOI: 10.1109/19.893269.

[11] A.A. SILVERIO, R.S. J. REYES, and W.Y. CHUNG, A Low Power High CMRR CMOS Instrumentation Amplifier Based on Differential Voltage - Current Conveyor for Beta-Dispersion Range Bio-Impedance Applications, Recent Researches in Circuits, Systems, Multimedia and Automatic Control, 2012, pp.31-36.

[12] A. Panchal, P.K. Jain, and D.S. Ajnar, Instrumentation Amplifier using Differential voltage second generation current conveyor (DVCCII) in standard $0.18 \mu \mathrm{m}$ CMOS technology, International Journal of Engineering Science and Technology (IJEST), Vol. 3,2011 .

[13] L. Safari, and Sh. Minaei, A Novel Resistor-Free Electronically Adjustable Current-Mode Instrumentation Amplifier, Circuits, Systems, and Signal Processing, Vol. 32, Issue. 3, June 2013, pp 1025-1038. DOI https://doi.org/10.1007/s00034-012-9522-y.

[14] Safari, Leila, and Shahram Minaei. "New ECCII-based electronically controllable current-mode instrumentation amplifier with high frequency performance." Circuit Theory and Design (ECCTD), 2017 European Conference on. IEEE, 2017. DOI: 10.1109/ECCTD.2017.8093343.

[15] Das, Devarshi Mrinal, et al. "Design considerations for high-cmrr low-power current mode instrumentation amplifier for biomedicai data acquisition systems." Electronics, Circuits and Systems (ICECS), 2014 21st IEEE International Conference on. IEEE, 2014. DOI: 10.1109/ICECS.2014.7049969.

[16] M'Harzi, Zineb, Mustapha Alami, and Farid Temcamani. "A novel high bandwidth current mode instrumentation amplifier." Microelectronics (ICM), 2015 27th International Conference on. IEEE, 2015. DOI: 10.1109/ICM.2015.7438048.

[17] Eldeeb, Mohammed A., et al. "A 0.4-V Miniature CMOS Current Mode Instrumentation Amplifier." IEEE Transactions on Circuits and Systems II: Express Briefs 65.3 (2018): 261-265. DOI: 10.1109/TCSII.2017.2685589.

[18] Han, Myungjin, et al. "Bulk switching instrumentation amplifier for a high-impedance source in neural signal recording." IEEE Transactions on Circuits and Systems II: Express Briefs 62.2 (2015): 194-198. DOI: 10.1109/TCSII.2014.2368615. 
[19] Kumngern, Montree, and Fabian Khateb. "A low-voltage and low-power multiple-input floating-gate FDCCII." Electrical Engineering/Electronics, Computer, Telecommunications and Information Technology (ECTI-CON), 2015 12th International Conference on. IEEE, 2015. DOI: 10.1109/ECTICon.2015.7206943.

[20] E.A. Sobhy and A.M. Soliman, Realizations of fully differential voltage second generation current conveyor with an application, International Journal of Circuit Theory and Applications; Vol. 38, Issue. 5, 2010, pp. 441-452. DOI: 10.1002/cta.566.

[21] Suwansawang, Sopapun, and Thawatchai Thongleam. "A 1-V bulk-driven CMOS fully differential second-generation current conveyor." Intelligent Signal Processing and Communications Systems (ISPACS), 2013 International Symposium on. IEEE, 2013. DOI: 10.1109/ISPACS.2013.6704631.

[22] Caviglia, Stefano, et al. "A high-linearity design for rail-to-rail fully differential current conveyors." Electronics, Circuits and Systems (ICECS), 2014 21st IEEE International Conference on. IEEE, 2014. DOI: 10.1109/ICECS.2014.7050044.

[23] Malik, Shahid, et al. "A CCII-based relaxation oscillator as a versatile interface for resistive and capacitive sensors." Signal Processing and Integrated Networks (SPIN), 2016 3rd International Conference on. IEEE, 2016. DOI: 10.1109/SPIN.2016. 7566719.

[24] Choubey, Chandan Kumar, Gaurav Tiwari, and Sajal K. Paul. "CCII based multifunction inverse filter." Advances in Electronics, Communication and Computer Technology (ICAECCT), 2016 IEEE International Conference on. IEEE, 2016. DOI: 10.1109/ICAECCT.2016.7942574.

[25] Kumngern, Montree. "Three-input single-output voltage-mode universal filter using single FDCCII." Intelligent Signal Processing and Communication Systems (ISPACS), 2014 International Symposium on. IEEE, 2014. DOI: 10.1109/ISPACS.2014.7024469.

[26] Petrashin, Pablo, et al. "Oscillation-based test in a CCII-based bandpass filter." Circuits \& Systems (LASCAS), 2017 IEEE 8th Latin American Symposium on. IEEE, 2017. DOI: 10.1109/LASCAS.2017.7948042. 